\title{
Regulation of cytokine expression in human plasmacytoid dendritic cells by prostaglandin $\mathrm{I}_{2}$ analogues
}

\author{
C-H. Hung*,\#,ף, Y-T. Chuף, J-L. Suen*,+, M-S. Leeף, H-W. Changף, \\ Y-C. Lo ${ }^{\S}$ and Y-J. Jong*,\#,
}

ABSTRACT: Plasmacytoid dendritic cells (pDCs) are critical in controlling adaptive immunity, but the mechanisms governing cytokine expression remain incompletely defined. Analogues of prostaglandin $(P G) I_{2}$, such as iloprost, can modulate functions of myeloid dendritic cells, but their involvement in the regulation of human PDCs remains unknown. To this end, the regulatory role of $\mathrm{PGI}_{2}$ analogues on cytokine expression in pDCs was investigated.

Circulating pDCs were magnetically sorted with BDCA-4 cell isolation kits from human peripheral blood mononuclear cells and treated with varying concentrations of iloprost with or without the addition of Toll-like receptor agonists, or an I prostanoid (IP) receptor antagonist, CAY10449. The levels of tumour necrosis factor (TNF)- $\alpha$, interferon (IFN)- $\alpha$ and interleukin (IL)-10 were measured by ELISA.

lloprost induced IL-10 expression, but suppressed CpG oligodeoxynucleotide- (or imiquimod-) induced TNF- $\alpha$ and IFN- $\alpha$ production in pDCs. This effect was reversed by the addition of CAY10449. Forskolin, a cyclic adenosine monophosphate activator, conferred a similar modulating effect to that noted in iloprost-treated pDCs, although a higher concentration of forskolin was required to exert the same effect.

lloprost enhanced interleukin-10 and suppressed Toll-like receptor-mediated tumour necrosis factor- $\alpha$ and interferon- $\alpha$ production of human plasmacytoid dendritic cells via the I prostanoid receptor and, in part, the cyclic adenosine monophosphate pathway.

KEYWORDS: Dendritic cell, iloprost, interferon- $\alpha$, interleukin-10, prostaglandin, tumour necrosis factor- $\alpha$

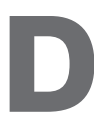
endritic cells (DCs) are highly heterogeneous in terms of their phenotypes and function, and are known to play a major role in initiation and regulation of adaptive immune responses [1-3]. The seemingly diverse function of DCs is, in part, dependent on the maturation stage and nature of the stimulating antigen and, importantly, the cytokines secreted upon activation. Notably, activated plasmacytoid DCs (pDCs) are capable of secreting type-I interferon (IFN), such as IFN- $\alpha$, and are critical in host immunity against viral infection. Also, the role of pDCs in the regulation of various diseases, including allergic, autoimmune diseases and cancer, has been documented. For example, IFN- $\alpha$ is elicited in virus-activated $\mathrm{pDCs}$ and participates in the induction of potent T-helper cell (Th) type 1 responses [4]. In contrast, tumour-infiltrating
pDCs from patients with ovarian cancer promote the induction of regulatory T-cells secreting interleukin (IL)-10, an anti-inflammatory cytokine [5]. Interestingly, the products of tumour cells have been shown to inhibit IFN- $\alpha$ production and antigen-presenting capacity by pDCs [6]. In a mouse model of asthma, depletion of pDCs led to a polarised Th2 response and the cardinal features of asthma, while transfer of pDCs in naïve mice before sensitisation prevented the occurrence of pulmonary allergic response, suggesting their protective role in lung inflammation [7]. It has also been noted that the number of pDCs increased significantly in bronchoalveolar lavage fluid $24 \mathrm{~h}$ after allergen challenge in patients with asthma [8] Thus, accumulated evidence to date has indicated the importance of $\mathrm{pDCs}$ in the regulation of disease expression and progression and also, depending on

\section{AFFILIATIONS}

*Graduate Institute of Medicine, College of Medicine,

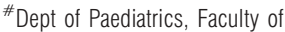
Paediatrics,

+Dept of Microbiology, Faculty of Medicine, College of Medicine,

"Dept of Paediatrics,

${ }^{f}$ Dept of Laboratory Medicine, all

Kaohsiung Medical University

Hospital, and

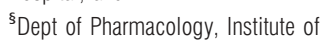

Medicine, Kaohsiung Medical

University, Kaohsiung, Taiwan

\section{CORRESPONDENCE}

Y-J. Jong

Dept of Paediatrics, Kaohsiung Medical University Hospital, NNo. 100

Tz-You 1st Road, Kaohsiung 807,

Taiwan.

Fax: 88673213931

E-mail: yjjong@kmu.edu.tw

Received:

May 062008

Accepted after revision:

September 272008

\section{SUPPORT STATEMENT}

Supported by a grant from the Centre of Excellence, Environmental Medicine, Kaohsiung Medical University Research Foundation, №. KMU-EM-97-2.2a, and a grant from Kaohsiung Medical University Hospital, No. KMUH96-6R03 (both Kaohsiung, Taiwan)

\section{STATEMENT OF INTEREST}

None declared. 
the stimulus and the cytokines produced, pDCs can be either immunostimulatory or tolerogenic. While these functional features have been demonstrated, the exact mechanisms by which pDCs are regulated are as yet undefined.

In this regard, it is of interest to note that while prostaglandins (PGs) are initially thought of as pro-inflammatory molecules, prostacyclin $\left(\mathrm{PGI}_{2}\right)$ has been shown to possess anti-inflammatory activity via the cyclic adenosine monophosphate (cAMP) pathway [9]. Because $\mathrm{PGI}_{2}$ is very unstable, $\mathrm{PGI}_{2}$ analogues with a higher chemical stability have been used in clinical application, of which iloprost, a stable $\mathrm{PGI}_{2}$ analogue, is a wellaccepted medication for pulmonary arterial hypertension, acting as a vasodilator by binding to the I prostanoid (IP) receptor. Recent evidence from the use of animal models suggests that signalling via this receptor also suppresses the features of asthma via inhibition of airway myeloid DC (mDC) function in vivo [10]. It is at present unknown, however, as to whether IP receptor activation and/or iloprost have any functional effect on pDCs. Considering the importance of pDCs in various disease contexts, the current authors have examined the in vitro effects of two $\mathrm{PGI}_{2}$ analogues, iloprost and treprostinil, on the generation of three regulatory cytokines in human pDCs and have provided, for the first time, functional evidence supporting a novel role of $\mathrm{PGI}_{2}$ analogues in the regulation of pDC function.

\section{METHODS}

\section{Isolation and analysis of pDCs}

Peripheral blood mononuclear cells were isolated from five healthy individuals with no history of systemic disease, after obtaining informed consent. Circulating pDCs were magnetically sorted by centrifugation with BDCA-4 cell isolation kits (Miltenyi Biotec, Bergisch Gladbach, Germany), following the manufacturer's instructions. Each experiment was repeated three times. In all cases, the purity of isolated pDCs was $>92 \%$ (see online supplementary material), as judged by their expression of CD123 but not CD14 markers on their surface by flow cytometry (data not shown). Purified pDCs $\left(2 \times 10^{5}\right.$ cells $^{*}$ condition $\left.^{-1}\right)$ were treated with varying doses of IP receptor agonists, iloprost or treprostinil, or a cAMP activator, forskolin, for $2 \mathrm{~h}$ and then stimulated with $10 \mu \mathrm{g} \cdot \mathrm{mL}^{-1}$ of $\mathrm{CpG}$ oligodeoxynucleotide (ODN)-2216 or imiquimod as previously described [11, 12], for 48 or $72 \mathrm{~h}$. For analysis of IFN- $\alpha$, pDCs were pre-treated with IL-3 $\left(10 \mathrm{ng} \cdot \mathrm{mL}^{-1}\right)$ [13] for $30 \mathrm{~min}$ prior to the treatment with iloprost, followed by the stimulation of the cells with $\mathrm{CpG}$ or imiquimod. To examine the involvement of the iloprost-IP receptor axis, pDCs were pre-treated with an IP receptor antagonist, CAY10449, $1 \mathrm{~h}$ before the treatment of the cells with iloprost. The production of cytokines in the culture supernatants was determined by ELISA for IL-10, IFN- $\alpha$ and TNF- $\alpha$ (R\&D Systems Inc., Minneapolis, MN, USA).

\section{Statistical analysis}

All data are presented as mean \pm SD. Change in cytokines at different doses of iloprost and treprostinil were analysed using the Wilcoxon signed rank test. Differences between experimental and control groups were analysed using the MannWhitney U-test. A p-value $<0.05$ was considered indicative of significant between-group differences.

\section{RESULTS \\ Iloprost induced IL-10 production, but inhibited Toll-like receptor-mediated expression of TNF- $\alpha$ and IFN- $\alpha$}

To examine the potential effect of $\mathrm{PGI}_{2}$ analogues on the expression of cytokines in pDCs, pDCs from a total of five nonallergic subjects were treated with varying doses of iloprost $\left(10^{-9}-10^{-7} \mathrm{M}\right)$ either alone or in combination with Toll-like receptor (TLR) agonists, CPG ODNs or imiquimod, or with varying concentrations of treprostinil. The results showed that iloprost was capable of inducing, in a dose-dependent manner, IL-10 production in pDCs (fig. 1a), whereas no significant enhancement of IL-10 in pDCs was noted when another $\mathrm{PGI}_{2}$ analogue, treprostinil $\left(10^{-9}\right.$ and $\left.10^{-7} \mathrm{M}\right)$, was used as a stimulus for $48 \mathrm{~h}$ (fig. 1b). Interestingly, while iloprost alone was unable to elicit TNF- $\alpha$ expression, iloprost could suppress CpGinduced TNF- $\alpha$ production (fig. 1c). To determine whether iloprost downregulation of CpG-stimulated TNF- $\alpha$ was IL-10 dependent, anti-IL-10 antibody $\left(0.1 \mu \mathrm{g} \cdot \mathrm{mL}^{-1}\right.$; R\&D Systems Inc.) was used for neutralisation of IL-10 bioactivity during the experiment. Neutralised anti-IL-10 antibody could not influence the suppressive effect of iloprost on CpG-stimulated TNF- $\alpha$ expression in pDCs (fig. 1d). Additionally, treprostinil was not effective in modulating the expression of CpG- (or imiquimod-) induced TNF- $\alpha$ production in pDCs (fig. 1e). To investigate the ability of $\mathrm{PGI}_{2}$ analogues to affect IFN- $\alpha$ expression, pDCs were first pre-treated with IL-3, followed by the treatment of the cells with $\mathrm{PGI}_{2}$ analogues and TLR agonists since, in the current authors' experience, CpG ODNs were unable to induce IFN- $\alpha$ production in $\mathrm{pDCs}$ without a brief "priming" by IL-3 [13]. As shown in figure 2, iloprost (fig. 2a) and treprostinil (fig. 2b) could suppress CpG- or imiquimod-induced IFN- $\alpha$ production in IL-3-primed pDCs. Note that, during this culture period, there was no significant difference in the expression levels of DC maturation markers, including CD86, CD80 and HLA-DR expression, as judged by flow cytometry (data not shown).

\section{IP receptor antagonist could reverse the effects of iloprost on pDCs}

It is known that $\mathrm{PGI}_{2}$ analogues, such as iloprost, exert their function through the IP receptor, leading to increased levels of intracellular cAMP [9]. To examine whether, indeed, the effect of $\mathrm{PGI}_{2}$ analogues was mediated through the IP receptor, $\mathrm{pDCs}$ were pre-treated with an IP receptor antagonist, CAY10449. The effects of iloprost on the cytokine expression in pDCs were then analysed. As shown in figure 3, the addition of CAY10449 was able to reverse iloprost-enhanced IL-10 expression (fig. 3a), and the inhibitory effect of iloprost on TLR-mediated TNF- $\alpha$ and IFN- $\alpha$ production was abrogated (fig. $3 b$ and c). Next, it was examined whether increasing intracellular cAMP in pDCs could confer the modulatory effect of iloprost, using a cAMP activator, forskolin. The results showed that treatment of the cells with forskolin showed similar modulatory effects on cytokine expression to those found in iloprost-treated cells. As seen in figure $3 d$, forskolin was able to enhance IL-10 production, and an inhibitory activity of forskolin on TLRmediated induction of TNF- $\alpha$ and IFN- $\alpha$ was revealed (fig. $3 \mathrm{e}$ and $\mathrm{f}$ ). However, on a molar basis, iloprost was shown to be more potent than forskolin on the regulation of cytokine expression in pDCs. These data suggest the involvement of the 

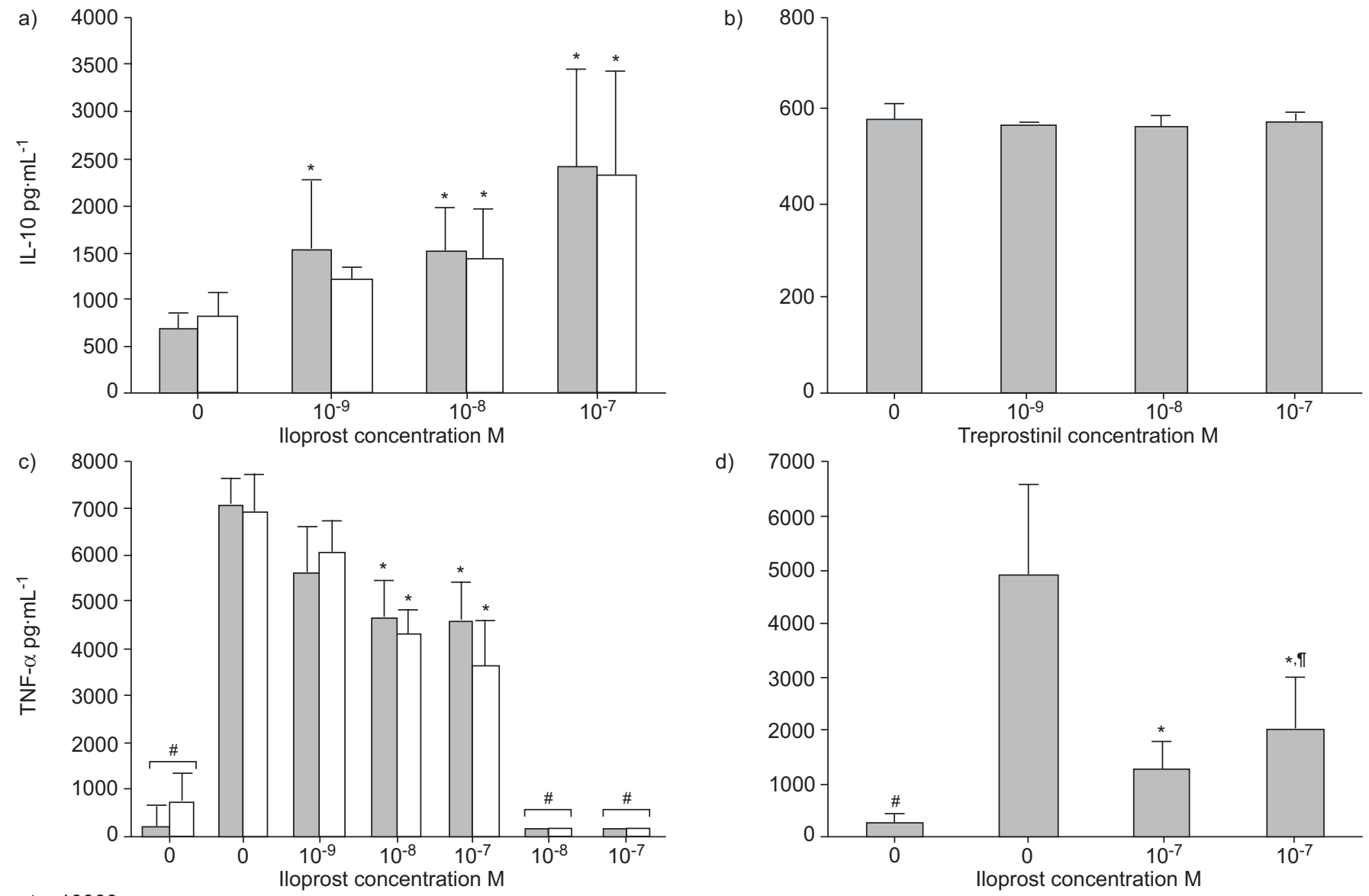

d)
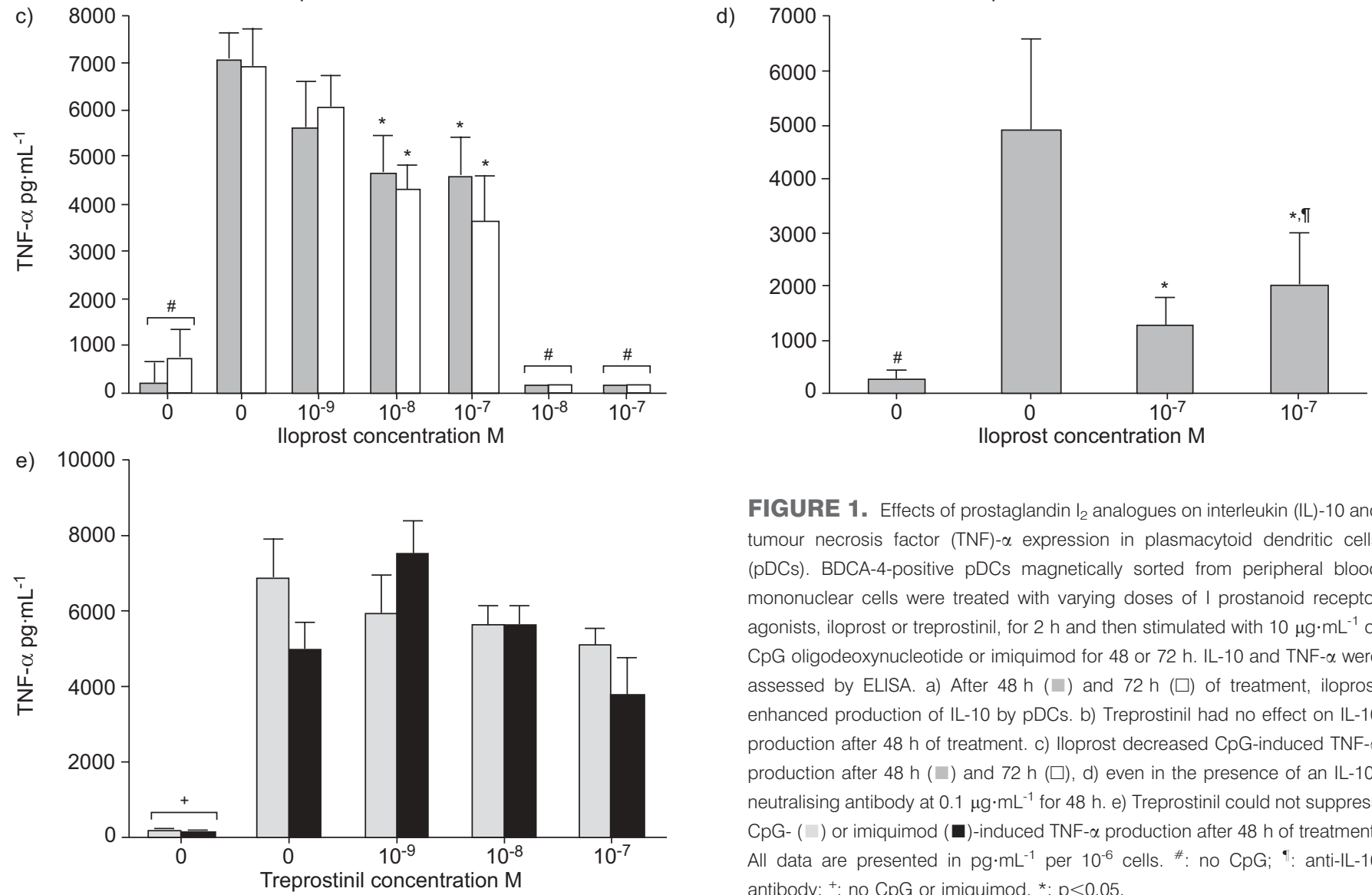

FIGURE 1. Effects of prostaglandin $I_{2}$ analogues on interleukin (IL)-10 and tumour necrosis factor (TNF)- $\alpha$ expression in plasmacytoid dendritic cells (pDCs). BDCA-4-positive pDCs magnetically sorted from peripheral blood mononuclear cells were treated with varying doses of I prostanoid receptor agonists, iloprost or treprostinil, for $2 \mathrm{~h}$ and then stimulated with $10 \mu \mathrm{g} \cdot \mathrm{mL}^{-1}$ of CpG oligodeoxynucleotide or imiquimod for 48 or $72 \mathrm{~h}$. IL-10 and TNF- $\alpha$ were assessed by ELISA. a) After $48 \mathrm{~h}(\square)$ and $72 \mathrm{~h}(\square)$ of treatment, iloprost enhanced production of IL-10 by pDCs. b) Treprostinil had no effect on IL-10 production after $48 \mathrm{~h}$ of treatment. c) lloprost decreased CpG-induced TNF- $\alpha$ production after $48 \mathrm{~h}(\square)$ and $72 \mathrm{~h}(\square)$, d) even in the presence of an IL-10neutralising antibody at $0.1 \mu \mathrm{g} \cdot \mathrm{mL}^{-1}$ for $48 \mathrm{~h}$. e) Treprostinil could not suppress CpG- $(\square)$ or imiquimod $(\square)$-induced TNF- $\alpha$ production after $48 \mathrm{~h}$ of treatment. All data are presented in pg. $\mathrm{mL}^{-1}$ per $10^{-6}$ cells. ${ }^{*}$ : no $\mathrm{CpG}$; ${ }^{\uparrow}$ : anti-IL-10 antibody; ${ }^{+}$: no $\mathrm{CpG}$ or imiquimod. *: $p<0.05$.

IP receptor and cAMP pathway in conferring the modulatory effects of iloprost on the expression of cytokines in pDCs.

\section{DISCUSSION}

DCs are emerging as chief orchestrators of immune responses, and two DC subsets, mDCs and pDCs [14], are known to exert their regulatory functions through the release of cytokines following activation and/or inflammatory insults; however, the exact regulatory mechanisms remain to be elucidated. Thus, understanding of the regulatory pathway controlling the expression of cytokines in pDCs would help in advancing the knowledge about the function of pDCs and their involvement in adaptive immunity. Evidence is provided herein supporting

a role of the IP receptor and $\mathrm{PGI}_{2}$ analogues in the regulation of pDC function through their modulatory activities on the expression of cytokines, adding a new dimension to the existing regulatory network in pDCs.

PGs are generated by stepwise conversion of arachidonic acid into a series of products, including PGG, PGH, $\mathrm{PGD}_{2}, \mathrm{PGE}_{2}$, $\mathrm{PGF}_{2 \alpha}$ and $\mathrm{PGI}_{2}$, via the action of the cyclooxygenases and other specific enzymes $[15,16]$. PGs are generally regarded as proinflammatory molecules, but $\mathrm{PGE}_{2}$ can have anti-inflammatory and anti-asthmatic effects via the E prostanoid receptor 3 [17]. $\mathrm{PGI}_{2}$ is a lipid mediator with vasodilatory and anti-thrombotic effects, used in the treatment of vasoconstrictive/ischaemic diseases, including pulmonary arterial hypertension. Inhaled 

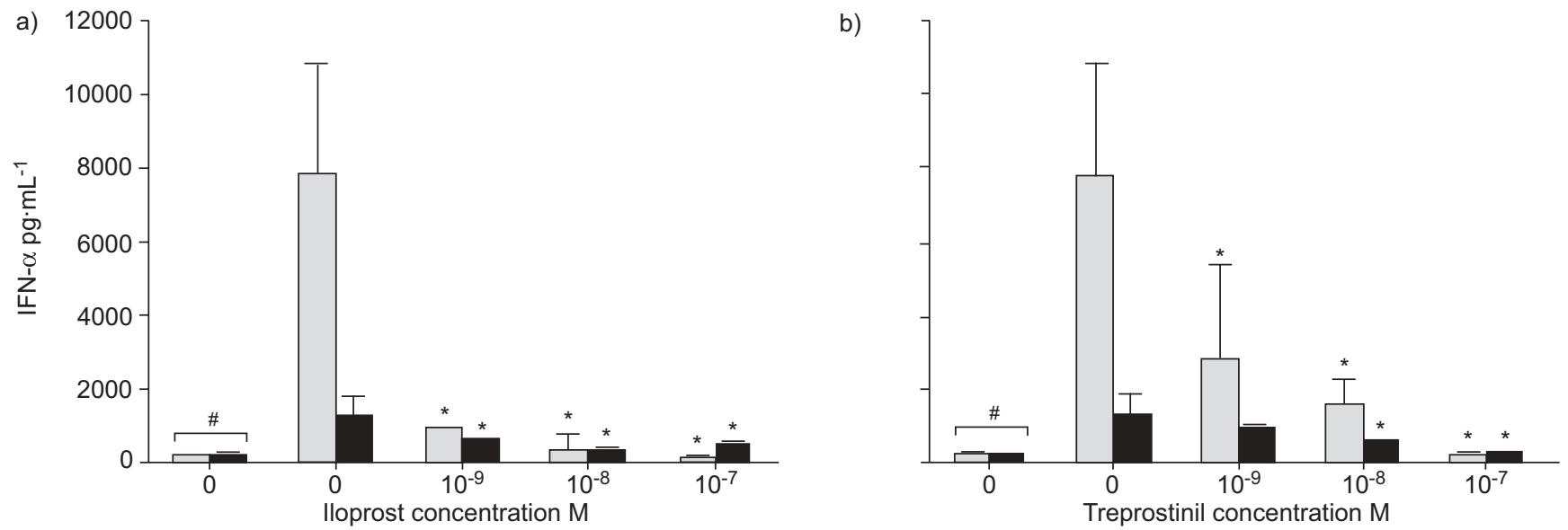

FIGURE 2. Effects of prostaglandin $I_{2}$ analogues on interferon (IFN)- $\alpha$ expression in plasmacytoid dendritic cells (pDCs). BDCA-4-positive pDCs magnetically sorted from peripheral blood mononuclear cells were treated with varying doses of I prostanoid receptor agonists, iloprost or treprostinil, for $2 \mathrm{~h}$ and then stimulated with $10 \mu \mathrm{g} \cdot \mathrm{mL}^{-1}$ of CpG oligodeoxynucleotide or imiquimod for $48 \mathrm{~h}$. IFN- $\alpha$ was assessed by ELISA. a) Iloprost and b) treprostinil could suppress CpG- ( $\square$ ) or imiquimod ( $\square$ )-induced IFN- $\alpha$ production by interleukin (IL)-3-primed pDCs. All data are presented in $\mathrm{pg} \cdot \mathrm{mL}^{-1}$ per $10^{-6}$ cells. ${ }^{*}$ : no CpG or imiquimod or IL-3 priming. *: $\mathrm{p}<0.05$.

iloprost, a stable $\mathrm{PGI}_{2}$ analogue, is used clinically as a drug treatment for patients with pulmonary arterial hypertension. The present results showed that treatment of pDCs with iloprost resulted in differential effects on cytokine expression. Iloprost inhibited the production of TNF- $\alpha$, but increased IL-10 production by pDCs. TNF- $\alpha$ may induce acute phase response protein and also play an important role in asthma [18]. IL-10 plays an important role in suppression of inflammatory responses by inhibiting multiple pro-inflammatory cytokine expression. Therefore, the functional effect of iloprost in suppressing TLRmediated pro-inflammatory cytokine expression while increasing IL-10 production in pDCs suggests its anti-inflammatory function.

The findings that CAY10449, an IP receptor antagonist, could reverse, at least in part, the effects of iloprost suggest the involvement of the IP receptor and cAMP pathway in mediating the effect of iloprost. As a corollary, iloprost has been shown to modulate cytokine response via the IP receptor, cAMP and nuclear factor- $\mathrm{KB}$ pathways in mouse bone marrowderived myeloid-type DCs [9]. However, treprostinil, another IP receptor antagonist, could not enhance IL-10 production in pDCs. Indeed, different $\mathrm{PGI}_{2}$ analogues have been shown to exert differential effects involving different PG receptors. For example, it is noted that iloprost failed to suppress alveolar macrophages, while treprostinil, a longer-acting $\mathrm{PGI}_{2}$ analogue, inhibited phagocytosis, bacterial killing and cytokine generation in alveolar macrophages to a much greater degree than the other $\mathrm{PGI}_{2}$ analogues and more closely resembled the effects of $\mathrm{PGE}_{2}$ [19]. Furthermore, iloprost is able to bind with higher affinity to the IP receptor [20]. Thus, the differential activity of iloprost versus treprostinil analogues seen in the present study may reflect their difference in the nature and type of receptor occupancy. It is of note that, when the levels of TLR-mediated TNF- $\alpha$ and IFN- $\alpha$ production in pDCs were analysed, iloprost and treprostinil revealed difference, both quantitatively and qualitatively, in their capacities to modulate these two cytokines. It is also noteworthy that, unlike in the case of viral infection, CpG ODN-mediated IFN- $\alpha$ production in pDCs requires an initial priming of the cells with IL-3 [11, 13], although the molecular basis for this requirement remains to be elucidated. The current results demonstrated that, in the presence of iloprost (or treprostinil), TLR-mediated IFN- $\alpha$ expression was inhibited in IL-3-primed pDCs. While, at present, it cannot be conclusively discerned whether the suppressive effect of $\mathrm{PGI}_{2}$ analogues on IFN- $\alpha$ production in pDCs is, in part, via its ability to downregulate IL-3 signalling, preliminary data suggest an alteration of IL-3-mediated activation of STAT5 (signal transducer and activator of transcription) in iloprost-treated pDCs (C-H. Hung; personal communication). These results suggest, therefore, the existence of a complex regulatory pathway involved in cytokine regulation in pDCs, and the detailed signalling events associated with differential cytokine responses await further investigation.

It is of interest to note that, in mice depleted of pDCs, iloprost suppressed the cardinal features of asthma via inhibition of airway $\mathrm{mDC}$ function through, in part, the induction of IL-10 [10]. The fact that the role of pDCs in the regulation of pulmonary allergic responses has been shown [7], and that iloprost also targets pDCs and induces IL-10 production, suggests a possible involvement of pDCs in contributing to the regulatory function of iloprost seen in the lungs. Therefore, iloprost, a well-accepted medication, may enhance tolerogenic function of both pDCs and mDCs by enhancing IL-10 and suppressing TNF- $\alpha$ production, suggesting its potential utility in asthma therapy. It is noted, however, that iloprost was able to suppress TLR-mediated induction of another regulatory cytokine, IFN- $\alpha$, in pDCs. IFN- $\alpha$ from $\mathrm{pDCs}$ has been suggested to play a role in conferring the protective effect in pulmonary allergic inflammation and, in fact, significantly lower amounts of virus-induced IFN- $\alpha$ is seen in allergic asthmatic patients when compared with healthy children or those with intrinsic asthma [21]. Further work is, thus, required to evaluate the potential use of iloprost and/or IP agonists in asthma. Interestingly, type-I interferons, including IFN- $\alpha$, and TNF- $\alpha$ are critically involved in the pathogenesis of 

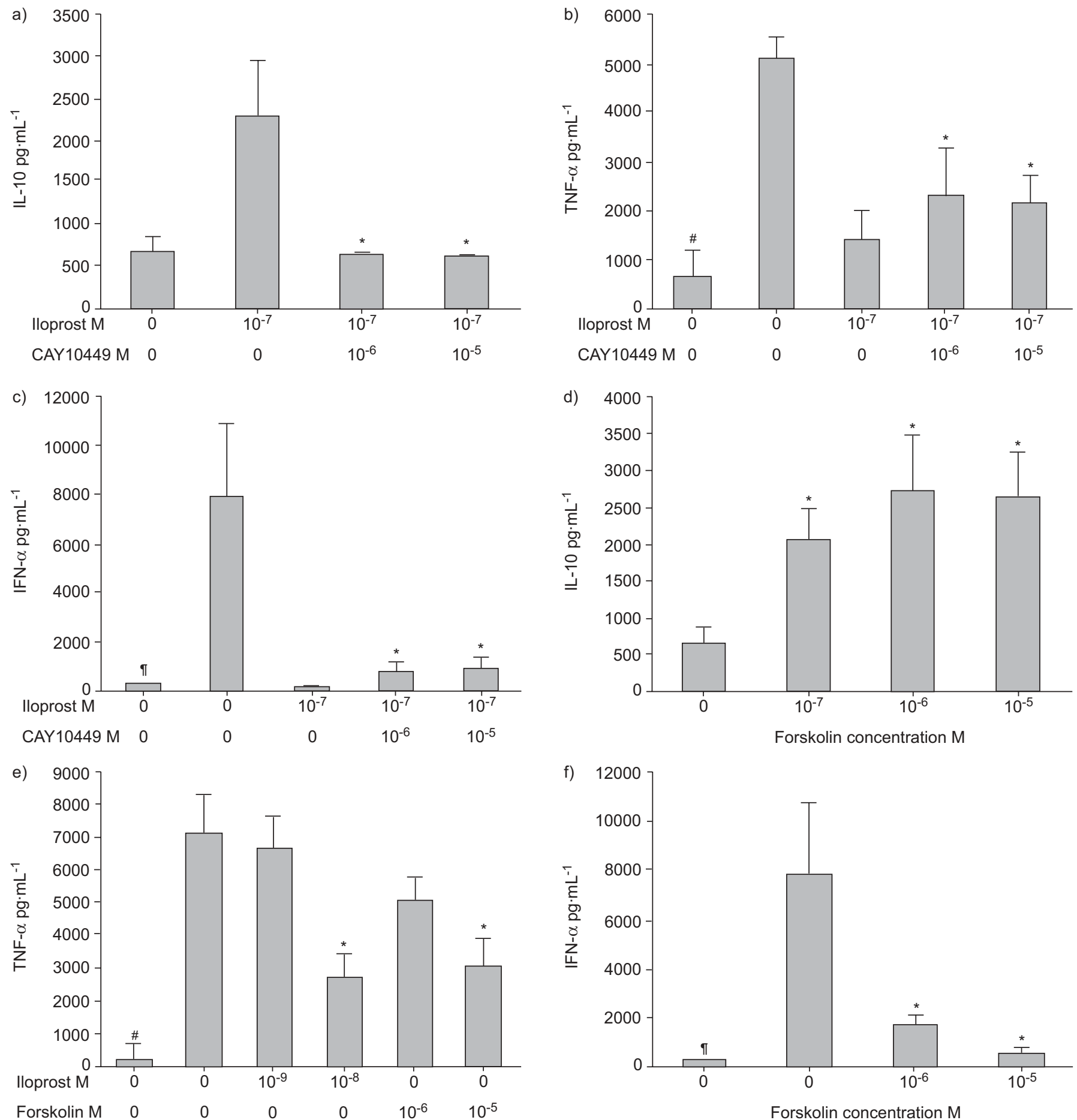

FIGURE 3. The effect of iloprost on plasmacytoid dendritic cells (pDCs) was via the I prostanoid (IP) receptor and cyclic adenosine monophosphate (cAMP) pathway. To determine whether the effect of iloprost on interleukin (IL)-10, tumour necrosis factor (TNF)- $\alpha$ and interferon (IFN)- $\alpha$ expression in pDCs was via the IP receptor-CAMP pathway, pDCs were pre-treated with an IP receptor antagonist, CAY 10449, for $1 \mathrm{~h}$ before treatment with iloprost or a cAMP activator, forskolin, for $2 \mathrm{~h}$ then stimulation with $10 \mu \mathrm{g} \cdot \mathrm{mL}^{-1}$ of $\mathrm{CpG}$ oligodeoxynucleotide for $48 \mathrm{~h}$. For analysis of IFN- $\alpha$, pDCs were pre-treated with IL-3. CAY10449 could reverse iloprost-enhanced a) IL-10 expression and iloprost-reduced b) TNF- $\alpha$ and c) IFN- $\alpha$ production by pDCs. High doses of forskolin d) enhanced IL-10, e) decreased CpG-induced TNF- $\alpha$ and f) decreased CpG-induced IFN- $\alpha$ production by pDCs, in a similar manner to iloprost. All data are presented in pg.mL ${ }^{-1}$ per $10^{-6}$ cells. *: no CpG; ": no CpG or IL-3 priming. *: p<0.05.

autoimmune diseases and may be a target of treatment in systemic lupus erythematosus and rheumatoid arthritis [22, 23]. The results of the present study showed that iloprost could significantly suppress TNF- $\alpha$ and IFN- $\alpha$ and induce IL-10 expression in $\mathrm{pDCs}$, suggesting the candidacy of iloprost as a modulatory agent in these diseases. 
Thus, how I prostanoid receptor signalling integrates in the Toll-like receptor-mediated activation of plasmacytoid dendritic cells may represent a novel mechanism in plasmacytoid dendritic cell function, and the current results would offer an experimental basis for prostaglandin $I_{2}$ analogues and the I prostanoid receptor signalling pathway as potential targets for modulation.

\section{REFERENCES}

1 Reid SD, Penna G, Adorini L. The control of $\mathrm{T}$ cell responses by dendritic cell subsets. Curr Opin Immunol 2000; 12: 114-121.

2 Banchereau J, Briere F, Caux C, et al. Immunobiology of dendritic cells. Annu Rev Immunol 2000; 18: 767-811.

3 Soumelis V, Liu YJ. From plasmacytoid to dendritic cell: morphological and functional switches during plasmacytoid pre-dendritic cell differentiation. Eur J Immunol 2006; 36: 2286-2292.

4 Fonteneau JF, Gilliet M, Larsson M, et al. Activation of influenza virus-specific CD4+ and CD8+ T cells: a new role for plasmacytoid dendritic cells in adaptive immunity. Blood 2003; 101: 3520-3526.

5 Curiel TJ, Cheng P, Mottram P, et al. Dendritic cell subsets differentially regulate angiogenesis in human ovarian cancer. Cancer Res 2004; 64: 5535-5538.

6 Hartmann E, Wollenberg B, Rothenfusser S, et al. Identification and functional analysis of tumor-infiltrating plasmacytoid dendritic cells in head and neck cancer. Cancer Res 2003; 63: 6478-6487.

7 de Heer HJ, Hammad H, Soullié T, et al. Essential role of lung plasmacytoid dendritic cells in preventing asthmatic reactions to harmless inhaled antigen. J Exp Med 2004; 200: 89-98.

8 Bratke K, Lommatzsch M, Julius P, et al. Dendritic cell subsets in human bronchoalveolar lavage fluid after segmental allergen challenge. Thorax 2007; 62: 168-175.

9 Zhou W, Hashimoto K, Goleniewska K, et al. Prostaglandin $\mathrm{I}_{2}$ analogs inhibit proinflammatory cytokine production and $\mathrm{T}$ cell stimulatory function of dendritic cells. J Immunol 2007; 178: 702-710.

10 Idzko M, Hammad $\mathrm{H}$, van Nimwegen $\mathrm{M}$, et al. Inhaled iloprost suppresses the cardinal features of asthma via inhibition of airway dendritic cell function. J Clin Invest 2007; 117: 464-472.
11 Guzylack-Piriou L, Balmelli C, McCullough KC, Summerfield A. Type-A CpG oligonucleotides activate exclusively porcine natural interferon-producing cells to secrete interferon- $\alpha$, tumour necrosis factor- $\alpha$ and interleukin-12. Immunology 2004; 112: 28-37.

12 Gibson SJ, Lindh JM, Riter TR, et al. Plasmacytoid dendritic cells produce cytokines and mature in response to the TLR7 agonists, imiquimod and resiquimod. Cell Immunol 2002; 218: 74-86.

13 Ito $\mathrm{T}$, Amakawa R, Inaba M, et al. Plasmacytoid dendritic cells regulate Th cell responses through OX40 ligand and type I IFNs. J Immunol 2004; 172: 4253-4259.

14 Shortman K, Liu YJ. Mouse and human dendritic cell subtypes. Nat Rev Immunol 2002; 2: 151-161.

15 Warner TD, Mitchell JA. Cyclooxygenases: new forms, new inhibitors, and lessons from the clinic. FASEB J 2004; 18: 790-804.

16 Helliwell RJ, Adams LF, Mitchell MD. Prostaglandin synthases: recent developments and a novel hypothesis. Prostaglandins Leukot Essent Fatty Acids 2004; 70: 101-113.

17 Kunikata T, Yamane H, Segi E, et al. Suppression of allergic inflammation by the prostaglandin E receptor subtype EP3. Nat Immunol 2005; 6: 524-531.

18 Mukhopadhyay S, Hoidal JR, Mukherjee TK. Role of TNF- $\alpha$ in pulmonary pathophysiology. Respir Res 2006; 7: 125-133.

19 Aronoff DM, Peres CM, Serezani CH, et al. Synthetic prostacyclin analogs differentially regulate macrophage function via distinct analog-receptor binding specificities. J Immunol 2007; 178: 1628-1634.

20 Narumiya S, Sugimoto Y, Ushikubi F. Prostanoid receptors: structures, properties, and functions. Physiol Rev 1999; 79: 1193-1226.

21 Gehlhar K, Bilitewski C, Reinitz-Rademacher K, Rohde G, Bufe A. Impaired virus-induced interferon- $\alpha 2$ release in adult asthmatic patients. Clin Exp Allergy 2006; 36: 331-337.

22 Lee PY, Reeves WH. Type I interferon as a target of treatment in SLE. Endocr Metab Immune Disord Drug Targets 2006; 6: 323-330.

23 Svenson M, Geborek P, Saxne T, Bendtzen K. Monitoring patients treated with anti-TNF- $\alpha$ biopharmaceuticals: assessing serum infliximab and anti-infliximab antibodies. Rheumatology 2007; 46: 1828-1834. 